\title{
A comparison of tobacco policy in the UK and Japan: if the scientific evidence is identical, why is there a major difference in policy?
}

Paul Cairney, Professor of Politics and Public Policy, University of Stirling, is a specialist in comparative public policy, currently focusing on using insights from public policy to inform contemporary debates on 'evidence-based policymaking' p.a.cairney@stir.ac.uk

Professor Mikine Yamazaki, Graduate School of Law, Hokkaido University, is a specialist in public administration, focusing in particular on the lessons from the UK for central-local relations in Japan.

Accepted for publication in Journal of Comparative Policy Analysis, published by Taylor and Francis. 


\section{Abstract}

Tobacco policy in the UK and Japan has diverged markedly. In the 1980s, both countries oversaw regimes with minimal economic and regulatory policies. Now, the UK has become one of the most, and Japan one of the least, controlled (advanced industrial) states. These developments are puzzling to public health scholars who give primary explanatory weight to scientific evidence and a vague notion of 'political will', because policymakers possessed the same evidence on the harms of tobacco, and made the same international commitment to comprehensive tobacco control. Instead, we identify the role of a mutually reinforcing dynamic in policy environments, facilitating policy change in the UK but not Japan: policymakers accepted the scientific evidence, framed tobacco as a public health epidemic, placed health departments at the heart of policy, formed networks with public health groups and excluded tobacco companies, and, accentuated socio-economic conditions supportive of tobacco control. This dynamic helps explain why the UK became more likely to select each tobacco policy control instrument during a series of "windows of opportunity'. Such analysis, generated by policy theory, is crucial to contemporary science/ practitioner debates on the politics of 'evidence-based policymaking': the evidence does not speak for itself, and practitioners need to know how to use it effectively in policy environments.

\section{Keywords}

Comparative policy - UK - Japan - tobacco control - policy environments - multiple streams approach - evidence-based policymaking

\section{Introduction}

Tobacco policies in the UK and Japan were similar in the 1980s. Both countries maintained policies that, by today's standards, indicate minimal control (Baggott, 1988: 5). Since then, the UK has produced one of the most, but Japan one of the least, comprehensive tobacco control policies among developed countries (Cairney et al, 2012: 148). Both have introduced many new policy instruments, but the UK's have been quicker, more restrictive, and more consistent with the World Health Organisation Framework Convention on Tobacco Control, despite that fact that both countries support the FCTC. 
These major differences are puzzling: policymakers faced similar conditions, possessed the same scientific evidence on the harms of smoking and passive smoking, initially responded in similar ways, but then produced very different policies. Public health accounts of such changes give most positive weight to the scientific evidence of harm and the campaigning efforts of public health groups, and negative weight to the cynical role of tobacco companies and lack of political will (2012: 6-9; Feldman and Bayer, 2004). The latter is too vague, and fails to account for key policy dynamics. Political science explanation often explores those dynamics by tracking the interaction between three Is institutions, ideas, interests - in each country. We go two steps further. First, we focus on the five main factors which constrain or facilitate attempts by policymakers to purse major change: the many actors interacting at multiple levels of government, the institutions or rules and norms in each venue, the networks which favour some actors over others, the dominant ideas or ways of thinking about particular problems, and socio-economic conditions and events (Cairney, 2016; Cairney and Heikkila, 2014).

We describe the interaction between these factors as the policy environments more or less conducive to policy change. This comparison helps explain policy divergence by focusing on the mutually reinforcing effects of each factor rather than trying to quantify their separate effects (Cairney et al, 2012; Cairney and Mamudu, 2014; Mamudu et al, 2015; Studlar and Cairney, 2014). It prompts us to identify: the key actors in multiple venues, their attempts to shift policymaking responsibility from some venues to others, the networks between policymakers and influential actors, the ways in which actors compete to frame policy problems and secure the dominance of one way of thinking, and the socioeconomic context to which they respond.

We identify an environment conducive to major tobacco control in the UK. Key policymakers became more likely to: accept the scientific evidence on the harm of smoking and passive smoking; frame tobacco routinely as a public health epidemic requiring a major government response; place health departments at the heart of policy development; form networks with medical and public health groups at the expense of tobacco companies; and, exploit reduced smoking prevalence and greater public support for control while downplaying the economic value of tobacco.

These developments did not take place in Japan. At the national level, policymakers remain likely to frame tobacco restrictions without reference to a public health 
'epidemic'; treasury departments are more central; they have strong and enduring links with a powerful tobacco company (JTI); and, they interpret socio-economic factors such as public behaviour and economics differently. Only in some sub-national governments did key policymakers frame tobacco as a public health issue which required stronger action.

Second, we enhance this broad explanation of policy change overall with in-depth analysis of the mechanisms of key changes in specific policy instruments. We use 'multiple streams' analysis to identify the specific sequence of factors and events that lead to discrete 'windows of opportunity' for each policy change (Kingdon, 1984; Jones et al, 2016). Drawing on the example of one key instrument - legislation to ban smoking in indoor public places - we show the dual importance of (a) a policy environment generally conducive to change, and (b) the motive and opportunity for policymakers to select particular solutions. This motivation is greater in the $\mathrm{UK}$, but each policy change remains contingent on timing and opportunity.

\section{Tobacco policy in the UK: a shift from minimal to comprehensive control}

UK post-war tobacco policy exhibits remarkably rapid policy change following decades of continuity (Cairney, 2007a: 45; Cairney et al, 2012: 99). In the late 1980s, most studies identified limited tobacco control and little prospect of change. Baggott (1988: 6) compared policy in Norway and the UK, identifying a similar focus of policy instruments but a major difference in weight: Norway introduced statutory measures to control practices such as advertising and including toxic ingredients in cigarettes, and the UK relied on voluntary agreements with the industry. By today's standards, the latter are considered to be ineffective and a reflection of a strong relationship between government and industry (Baggott, 1986; 2014). Most accounts confirmed the latter, which formed during World War Two and endured for decades (Read, 1992; Taylor, 1984; Baggott, 1988).

Since 2007, the UK has topped the 'tobacco control scale', measuring the implementation of a comprehensive set of control measures in Europe (Joossens and Raw, 2014). UK Government policy changes include: legislation to ban tobacco advertising (2002), ban smoking in almost all public places (2006), increase the minimum age for the sale of cigarettes from 16 to 18 (2007), introduce plain packaging for tobacco products (2015), and ban smoking in private cars with children present (2015); high levels of taxation designed to reduce smoking demand (from the 1980s), coupled with more customs enforcement; higher spending on smoking cessation services; and a shift towards 
unequivocal health education (see Cairney et al, 2012: 101-2).

There is some debate about the nature of UK policy change (Cairney, 2007a: 49), based on the extent to which voluntary measures represented a step towards, versus a way to delay, tobacco control (Baggott, 1986), and therefore if change has been incremental or punctuated (Studlar and Cairney, 2014: 514; Cairney et al, 2012: 104). However, all accounts identify major change since the 1980s.

There is more debate on the weight we should attach to specific sources of policy change. For example, globally speaking, centrist and left wing parties are generally more in favour of tobacco control than right-wing/ pro-business parties, but tobacco control generally does not prompt major partisan debate, and a 'moving consensus' develops when one party introduces controls and others do not reverse them (Author et al, 2012: 85; 154; 172). Still, in the UK, we witnessed a shift in approach from a centre-right Conservative party overseeing key policy changes (most notably, on taxation) but rejecting the European Union's agenda on measures such as bans on tobacco advertising (Duina and Kurzer, 2004: 67), to a centre-left Labour party which accelerated policy change significantly from 1997 and generally went far beyond minimum European Union standards. In that context, the EU also seems to be a key player, but is less influential than in countries, such as Germany, in which there is more resistance to change (indeed, a Germany-Japan comparison would be more useful to gauge the EU effect). Similarly, while, devolved governments (established in 1999) provided new venues sympathetic to tobacco control, they produced similar policies to the UK Government (Author, 2007) and facilitated issue expansion to a lesser degree than Albaek et al (2007) find in the US (Cairney, 2007a; Cairney et al, 2012: 106).

Most accounts explain change broadly with reference to two factors related to the "politics of evidence-based policymaking' (Cairney, 2016; Cairney et al, 2016): policymakers use 'rational' and 'irrational' shortcuts to turn too much information into a simple way to define and solve a policy problem; and, they do so within a policy environment that provides constraints and opportunities for action (Cairney, 2016; Cairney and Heikkila, 2014).

This focus helps us explain why the scientific evidence on smoking and then passive smoking was influential in the UK, but took two to three decades to translate into a proportionate policy response (Cairney et al, 2012: 117-8). The evidence - on the links 
between smoking and ill health (the problem), and regarding the most effective ways to discourage smoking (the solutions) only helps reduce uncertainty. Ambiguity remains because policymakers can understand a policy problem in different ways by accentuating one issue over another: smoking kills, but tobacco is an economically valuable product. Scientific evidence matters when actors use it successfully to reframe the ways in which policymakers primarily understand and seek to solve policy problems. In this case, it took decades to persuade policymakers to reconsider the dominant way of thinking about tobacco, from an economic good to be supported to a public health epidemic to be eradicated.

Public health actors faced two challenges, to persuade policymakers: to accept unequivocally the evidence on ill health from smoking (published from the 1950s, producing a medical response and an incremental government strategy from the 1960s) and passive smoking (published from the early 1980s but only 'set in stone' in government from 1998); and, to produce tobacco controls proportionate to the problem (Cairney, 2007a). In both cases, there was a significant gap between policymakers accepting the evidence on health, accepting the need for evidence-based interventions to reduce smoking, producing a proportionate response, and finally taking the need for 'comprehensive' tobacco control for granted (Cairney and Studlar, 2014).

These actions took place within a 'policy environment' which only began to facilitate rather than constrain major policy change after several decades, during which the following all took place: key policymakers reframed tobacco as a public health epidemic; they allowed health departments and units to take responsibility for tobacco control; so, key network dynamics shifted, from a post-war close network between the industry and government to the dominance of medical and public health groups; and, those groups helped exploit shifts in socio-economic conditions. Smoking prevalence in the UK was $82 \%$ for men and $41 \%$ for women in $1948,35 \%-31 \%$ in $1986,30 \%-26 \%$ in 1998 , and $22 \%-17 \%$ in 2015 (ASH, 2015). Reduced prevalence helped reduce opposition to tobacco control, and reduced tobacco tax revenue (from a high of $15 \%$ to a low of $3 \%$ of overall tax receipts) - combined with government commitments to reduce reliance on it - lessened the incentive to avoid greater control (Author et al, 2012: 115).

It is difficult to describe the primary driver of change when each dynamic reinforces the other, but we can still describe a crucial role for (a) scientific evidence, in contributing to public awareness and reduced prevalence, and (b) key actors seeking policy change. 
Tobacco control advocacy became more important from the 1980s: public health and epidemiological groups grew in stature and their attitudes hardened. An increasingly effective ASH (Action on Smoking and Health), set up (1971) by the influential Royal College of Physicians, joined with an increasingly organised British Medical Association (BMA) (and, eventually, key cancer charities such as CRUK) to generate support for tobacco control in the Department of Health (Cairney et al, 2012: 113). They used the evidence of smoking harm to challenge 'laissez faire' regulations within government and encourage shifts in public behaviour. This pressure helped prompt actors in government either to shift their primary understanding of tobacco or give way to actors in other venues more sympathetic to tobacco control. Actors in favour of control used multiple venues (the WHO, EU and devolved governments) and international experience to make the case for evidence-based solutions. So, evidence played a part in explanation but, 'no single factor explains this change. Rather, they are all necessary but insufficient conditions for major policy change' (2012: 120).

\section{Tobacco policy in Japan: explaining inertia and minimal change}

Tobacco policy in Japan did not follow the UK's trajectory. It is one of the least controlled advanced-industrial countries (Cairney et al, 2012: 144). In many ways, its national policy regime resembles that of the UK in the late 1980s: it has overseen the introduction of a smaller number of measures, less quickly, with a greater emphasis on voluntary measures, and with limited measures to ensure implementation: 'Until recently there were few central-level laws except for health warnings on cigarette packages [and] some limitations on smoking in public transportation' (2012: 148). Only from the 2000s did it begin to introduce major health warnings on cigarette packs, and significant tax rises on tobacco. Most other restrictions on smoking in public places are partial and voluntary, and only stronger in a very small number of prefectures such as Kanagawa (2012: 149). Some municipalities introduced regal regulations to ban smoking on city centre streets. Further, regulations of advertising tobacco on television, newspaper, magazine, and billboards and in public transportation have been introduced as a voluntary agreement since the 1980s (Levin, 2005).

This slower process of change takes place because the reinforcing dynamics that we identify in the UK - both specific (party and venue) and broad (policy environment) - are largely different from Japan. Japan generally does not elect left-wing parties more in favour of the state regulation of business, with one important exception: the election of the Democratic Party of Japan, taking power from 2009-12 and raising tobacco taxes by around 40\% in 2010 (Buerk, 2010). Rather, politicians of the centre-right and pro- 
business governing party have close relations with tobacco industry groups. According to research by the Japan Society of Tobacco Control (2014), the political federation of national tobacco sellers and the political federation of tobacco leaf farmers make major donations to the Liberal Democratic Party and over 100 LDP politicians. From 2010-12 it was $¥ 41$ million (approx. £ 0.29 million). Such donations receive minimal public attention compared to the likely reaction in the contemporary UK (although a $£ 1 \mathrm{~m}$ donation by Bernie Ecclestone to the Labour Party in 1998, allegedly to delay a sponsorship ban in Formula 1, was not as controversial as it should have been - Duina and Kurzer, 2004: 71).

Further, there is far less scope for issue expansion via venue shopping. In particular, there is no equivalent to the EU which can seek to enforce a tobacco control agenda on 'laggard' countries such as Germany (Author et al, 2012: 76). Japan is a signatory to the WHO's major global tobacco control agreement (the FCTC), and its set of comprehensive policy instruments, to: maintain high prices, protect individuals from second-hand smoke, regulate tobacco product ingredients, introduce health warning labels on at least $30 \%$ of the product, provide health education, ban tobacco advertising and promotion, support smoking cessation services, control the illegal trade of tobacco, ban sales to under-18s, support relevant litigation against the industry, support economic alternatives to tobacco leaf growing and manufacture, and monitor and implement the FCTC effectively (Mamudu et al, 2015: 860). However, its obligation and commitment to implementation is far less clear.

For example, on the one hand, the FCTC contributed to a revision of the enforcement regulation of the Tobacco Industrial Act to display warnings on health on packaging in Japan (Tanaka, 2014).and: "a handful of administrative actions, i.e., guidelines, white papers, and recommendations from central government agencies and their advisory bodies, have helped move forward a tobacco control policy agenda" (Levin, 2013: 480). On the other hand, there remains national opposition to a comprehensive ban on smoking in public places. The Health Promotion Act of 2002 had promoted voluntary selfregulation among owners and administrators of public facilities and workplaces. In 2011, the Ministry of Health, Labour and Welfare tried to amend the Industrial Safety and Health Act to enforce a ban on smoking in workplaces outside assigned smoking spaces. However, the Ministry gave up its introduction of the bill to the National Diet when likely majority opposition became clear (Tanaka, 2014). The government still encourages weak control measures - voluntary self-regulation, education, communication, training, and 
public awareness - and has not followed the FCTC stipulation to cut ties with the tobacco industry.

Such gaps, between commitment and action, can be explained broadly with reference to its policy environment which is far less conducive to tobacco control: policymakers frame tobacco restrictions without reference to a public health 'epidemic'; treasury departments are more central; they have strong and enduring links to the industry; and, they value the tobacco economy. So, the role of scientific evidence is often less apparent in Japan because key actors downplay its significance and weigh up its policy implications in economic terms.

The Ministry of Health, Labour and Welfare encourages the diffusion of "evidencedbased" information (Chief of Health Service Bureau of Ministry of Health, Labour and Welfare, 2010) and Japan produced some of the earliest evidence on passive smoking (Hirayama, 1981). Yet, policymakers are more likely to protect the tobacco industry, leaf tobacco farmers and small size business owners (Cairney et al, 2012: 58; 68; The Asahi Shimbun, 12/06/2012; The Mainichi Shimbun, 20/02/2014), by supporting positive economic frames and pursuing less effective tobacco control frames, including a focus on courtesy and the benefits of ventilation when identifying a policy solution to environmental tobacco smoke (Bialous et al., 2006).

The business of producing, selling and advertising of tobacco is regulated by the Tobacco Industry Act (1984). It prescribes "the sound development of national economy and . . . stable fiscal revenues" by advancing "the sound development of our nation's tobacco industry". The taxation of tobacco is also regulated by law and tobacco business in Japan is under the guidance of Ministry of Finance (Levin, 2005). Japanese policy on partial bans on smoking in public places also reflects some policymaker acceptance of the suggestion, promoted by tobacco companies but opposed by public health groups, that proper ventilation can minimise the health consequences of environmental tobacco smoke (Bialous et al., 2006). Tobacco control advocates, such as the Japan Society for Tobacco Control, remind policymakers that the scientific evidence on harm, and on effective policy instruments to reduce it, should translate into comprehensive tobacco control. However, there remains a significant gap between accepting the evidence on health, accepting the need for evidence-based interventions to reduce smoking, and pursuing a proportionate response with reference to the sense of urgency and epidemic fostered in countries like the UK. 
This greater attachment to an economic frame reflects and reinforces key dynamics which differentiate Japan from the UK: the Ministry of Finance has not given way to Health, a close network between the industry and government still exists, and, there is a smaller shift of policymaker attention from tobacco revenue and economic activity towards indicators of support for tobacco control such as shifts in public opinion or smoking prevalence (prevalence among men reached $80 \%$ before the 1970 s, falling to $30 \%$ by 2016; for women it peaked at 15\% and is now below 10\% - Author et al, 2012: 160; Japan Times, 2016).

The tobacco industry was once of major importance in both countries but a major challenge to its status has only happened in the UK. Crucially, the UK has a relatively pluralistic political culture to facilitate public competition between groups and highly public criticism of government and industry. In Japan, while public health and medical groups campaign for tobacco control, they do not lobby policymakers as aggressively and publicly as the UK's groups. There is no politically active public health profession to keep tobacco control on the agenda and maintain pressure on government. Evidence does not speak for itself (Author, 2016), and there are fewer actors to speak loudly for evidencedriven tobacco control.

Further, Japan Tobacco International was once owned by the Japanese government and enjoyed a monopoly over domestic production. One third of stock of JTI is still held by the government. It is now the third largest tobacco company in the world (Japan Tobacco Inc, 2015). JTI has 'immense financial resources to hire publicists, lobbyists, attorneys, and other personnel as needed' for its global tobacco lobbying efforts (Cairney et al, 2012: 62), as well as a reputation as a source of lucrative employment for former Ministry of Finance civil servants in Japan. They give it a continued presence in tobacco policy networks in Japan that are identifiable, albeit difficult to measure when using sources in the public record (Levin, 2005; 2013).

In the UK, tobacco taxation is 3-4\% of tax revenue and the government now favours high levels to discourage smoking rather than secure income. While tobacco revenue in Japan is not higher $(1.8 \%$ of national tax revenue and $3.1 \%$ of local tax revenue in 2014 - JTI, 2017), policymakers value it more highly. The Ministry of Finance values the convenience of a routine fiscal resource, alongside dividends from JTI, particularly during the current period in which the economy is fragile and the government would 
struggle politically to increase VAT or other major taxes. In addition, the Ministry of Finance shares taxation receipts with subnational governments, and so the benefit of tobacco taxation extends to several venues. Further, policymakers at multiple levels are reluctant to harm small businesses by, for example, introducing bans on smoking in bars and clubs. While tobacco industry influence often seems behind-the-scenes, small business groups are more vocal and seem more like veto-players: small business is important to politicians and no level of government would take the blame for business closures. This issue has specific significance because local governments often ban smoking in the street (partly to reinforce social manners), which makes it more difficult to ban smoking indoors. Instead, governments subsidise businesses to install ventilation and smoking rooms, particularly when bars are on high floors and it is inconvenient to smoke outside.

\section{Tobacco policy beyond the centre: the role of subnational policymaking}

These gaps between the UK and Japan at the national level could be offset by subnational policy developments. However, there is more evidence of policy innovation in the subnational UK, and only some spread of stronger tobacco control in a small number of Japanese prefectures. These differences reflect general UK/ Japan differences in devolution and the specific extent to which new venues provide new 'windows of opportunity' for tobacco policy change.

In the UK, subnational policy innovation reflects (a) the introduction of devolution in Scotland, Wales and Northern Ireland in 1999, which (b) reflects the calls from these territories for a level of political autonomy, linked to high levels of national identity (particularly in Scotland). Their level and strengths of responsibility vary, but all three direct health policy and most aspects of public health (although Wales and Northern Ireland rely on the UK Government to produce legislation). This takes place in a system in which there is a National Health Service under the control of the UK and devolved governments, a relatively strong distinction between UK and devolved policy responsibilities in health, and the relative absence of local authority involvement in most aspects of health delivery (Greer, 2004; Birrell, 2012; Keating, 2010; Cairney and Mamudu, 2014; Cairney, 2011).

This division of responsibilities has rarely translated into divergences in tobacco policy, because: the UK made major tobacco control changes before devolution; it still controls key aspects, such as the regulation of advertising, taxation, and customs enforcement; it committed the UK as a whole to the FCTC; the EU directs other measures, such as the 
regulation of ingredients; and, all the UK and devolved governments express a commitment to stronger tobacco control measures in areas such as health education, smoking cessation, and the regulation of smoking in indoor public places (Cairney, 2009; Asare et al, 2009).

In Japan, devolution has taken a very different form to the UK, reflecting an economic driver for self-government and the general absence of an identity-driven constitutional settlement (Cairney and Yamazaki, 2013). The concept of regionalism ('do shu sei') is relatively ambiguous, defined as creating a sub-governmental unit between the state and second-tier local government, and transferring administrative and fiscal powers to regional public bodies, which are branches of the national administration. Principal objectives relate to: regional economic development; administrative reforms to reduce the number of national civil servants; mergers of prefectural governments; and, integration of branches of functional ministries into one regional public entity to coordinate public policy (Yamazaki, 2010). Economics trumps health in devolution policy.

Further, there is less subnational autonomy than in the UK: the present two-layer Japanese central-local governmental system is characterised by the concept of uniformity, immobility and complementarity. In 1947, the revised constitution and Local Autonomous Law introduced homogeneous and uniform local government. Each prefectural government and municipality were in principle to be treated equally (Nishio, 2001). Further, Japan's central government is a vertical structure which is divided among functional ministries and lacks integrative powers to consolidate them at the centre or region. These functional ministries, and the Ministry of Internal Affairs and Communications (MIAC) in charge of local government and administration, have proven reluctant to allow exceptions in the local government system. The prefectures and municipalities tend to be uniformly managed (Kanai, 2007). Japanese central and subnational government also tend to seek cooperation and consensus, formally and informally, and to share responsibilities in areas such as healthcare and tobacco control (Yamazaki, 2015).

There is some evidence that the national government has reduced its supervisory role and increased the autonomy of local governments. For example, in 1999, the Comprehensive Law on Decentralisation enlarged the discretion of local governments through abolishing the system of agency delegation with the powers to impose central services on local governments. It also helped relax central government regulations of the staff, facilities 
and committees of local government (Nakano, 2010; Muramatsu et.al., 2001). This places most executive power in a governor or mayor, the chief executives of administrative departments, directly elected along with local assembly members by the electorate. The Local Autonomy Law authorises the governor and mayor to exert legislative power introducing by-laws, and the assembly to possess a power to pass any bills and introduce private members bill and committee bills (Ohsugi, 2008).

Consequently, local governments now have greater discretion to legislate by-laws, interpret laws and regulations differently, and introduce fines to regulate behaviour (Ministry of Internal Affairs and Communications, 2009). The Local autonomous Law was amended to redefine the general rules of administrative fine which can be enforced by local government. Since then, the number of local governments which introduced bylaws with administrative fines has been growing (Kitamura, 2003). This new competence has enabled them to produce distinctive public policies, such as by-laws banning smoking public places in two prefectural governments or banning smoking on the street in the area of city centre in a number of municipalities, although such policy innovation is still limited by central direction.

Overall, while policy remains centralised in terms of legal and financial systems, local governments are able to exert a certain degree of power (Rhodes, 1988; Samuels, 1983; Reed, 1986; Muramatsu, 1997; Ito, 2001). Consequently, there are some examples of subnational policy innovation, but the pressures for uniformity are so high that it takes a major expenditure of political will to innovate to a major extent. In both countries there is devolution, and therefore greater potential for issue expansion, but the central government public health agenda and scope for devolved government innovation in health are both stronger in the UK.

\section{From broad to specific explanation: case studies of policy instruments}

Detailed case studies allow us to turn a broad explanation of tobacco control, based on the use of scientific evidence in multi-level policy environments, into a specific series of decisions and events to produce key policy changes. Using the case study of case of bans on smoking in indoor public places, we demonstrate the need to combine a general discussion of policy trajectory with specific context, events, and choices to determine the fate of each policy instrument. Our expectation is that major policy changes in the UK are difficult while in Japan they often seem almost impossible.

To that end, we adapt Kingdon's (1984) multiple streams analysis, which describes the 
ways in which policy changes when three 'streams' come together during a window of opportunity: there is high attention to a policy problem; a solution exists; and, policymakers have the motive and opportunity to adopt it. We reinforce contemporary scholarship which highlights, for example, the role of policy transfer when solutions are developed in other countries and/ or sub-national jurisdictions do not have full control over the decision to import solutions (Ackrill et al, 2013; Bache \& Reardon, 2013; Cairney, 2009; Cairney and Jones, 2016; Cairney and Zahariadis, 2016; Jones et al, 2016; Liu et al, 2011; Zahariadis, 2014). In the case of smoking in public places, we examine examples in which: there was high attention to smoking as a public health problem; a solution, to ban smoking partially or completely in public places existed; but, policymakers had the opportunity to select one of many variants (strong or weak) of the same solution.

In the UK, all four governments eventually pursued an almost complete ban on smoking in indoor public places in the mid-2000s (followed by a ban on smoking in private cars with children present in 2015) but their 'windows of opportunity' differed in each case, based on:

- Attention to, and framing, the problem. There was high attention in all four areas in the early to mid-2000s, but actors used the evidence on public opinion differently: advocates of control highlighted opinion in favour of a smoking ban (around 80\%), while opponents highlighted the opposition to a full ban (also 80\% in many cases); advocates stressed majority support in government consultations, while opponents stressed equivocal survey opinion (Cairney, 2009: 478-9). For example, the UK Government identified low survey support (20\%) for a full ban when promoting exemptions for pubs and clubs, while the Scottish Government highlighted 56\% in favour of no exemptions in its consultation (2009: 479).

- The development of feasible solutions mediated in the policy community. It took time for interest groups to become interested in devolved policy in Wales and Northern Ireland, at least until the early to mid-2000s when it became clearer that there was scope for discrete policy change. In Scotland, medical and public health groups had a greater presence, working together in the cross party group to propose legislation (relatively unopposed by an industry that did not take devolution particularly seriously) (2009: 481). Further, while the UK Government was learning from US experience, in which key states introduced partial and incremental bans, the Irish experience of a complete ban had a marked 
influence on devolved agenda. The potential for devolved policy innovation then fed into Westminster debates on policy change for England (2009: 483).

- The motive and opportunity to select a solution. Labour was generally more in favour of some form of tobacco control, and was the party in government in each area bar Northern Ireland. In Northern Ireland there was cross party support for tobacco control to emulate that of Ireland (2009: 477). Wales was the first to express a commitment, but it lacked legislative powers. In Scotland, the opportunity for the Scottish National Party (then in opposition) to pursue a member's bill, representing the cross party parliamentary group on tobacco control, helped keep the issue high on the agenda (Cairney, 2007b). After some uncertainty and hesitancy, the Scottish Government was the first to pursue a comprehensive ban in 2005. Northern Ireland was the last to pay attention to this issue (during its suspension of devolution). All three devolved territories relied on direct support from the UK government to pursue their aims, but their actions also influenced the Westminster debate and subsequent vote for a full ban (Cairney, 2009: 476-7).

Consequently, there were four separate windows of opportunity in which attention to the problem varied, the same solutions were available, and policymakers in each territory had the motive to pursue different forms but often a limited opportunity to do so. Early devolved efforts, by the National Assembly for Wales and the Scottish Parliament member's bill, focused on areas such as public buildings and restaurants, with pubs and clubs initially exempt; their efforts were delayed by uncertainty over legislative competence; the subsequent successful Irish experience (coupled with party competition in Scotland) ensured that a full ban was technically and politically feasible; and, when policymakers had the ability to ensure change, their willingness to pursue greater restrictions was more apparent. In separate debate, the UK Government pursued a partial ban, initially exempting pubs and then only clubs, before MPs voted for a complete ban following unusually public health pressure and pub industry support (it preferred a full ban to the exemption for its competitor clubs) (2009: 481).

In other words, there is a strong element of contingency to the production of a comprehensive ban on smoking in public places, even when the UK policy environment had become relatively conducive to tobacco control (and the UK was a signatory to the FCTC). Crucially, in a country with a trajectory towards becoming the most controlled in Europe, a full ban on smoking in public places was not inevitable. A voluntary then partial 
ban was always a realistic possibility, and a full ban could only have happened in a particular point in time (from the mid-2000s) during a window of opportunity. This is key context in which to consider the reduced likelihood of a similar ban in any country including Japan - with a policy environment less conducive to control.

In Japan, the Kanagawa prefectural government first introduced the Passive Smoking Prevention By-Law (Regulation) in 2009 (a similar measure is in place in Hyogo in 2013). This policy resembles the partial ban first proposed by UK devolved governments and pursued in US states in the early 2000s. This more limited change relates to the different nature of the 'streams' in Japan:

- Attention to, and framing, the problem. One opinion poll, conducted by the prefectural government, showed that $88 \%$ of respondents ( $69 \%$ of smokers; $92 \%$ of non-smokers) agreed with restricting smoking in public places and there was some media support for the legislation (e.g., The Asahi Shimbun, 20/04/2008). These factors helped encourage the governor to introduce the legislation. However, the majority of restaurants, pubs, hotels and amusement facilities were small businesses, and most owners expressed dissent (Matsuzawa, 2009). Further, there still remained strong adherence to the idea of smoking as a personal choice or economically favourable product.

- The development of feasible solutions mediated in the policy community. Practices in other places, such as New York City, Ireland and Hong-Kong contributed to the discussion and development of policy options (Matsuzawa, 2009). However, although supportive of tobacco control, public health and medical groups did not lobby energetically, in public, to pass a bill. This reticence reflects a general tendency to have fewer campaigning resources, and to restrict their efforts largely to civil servants rather than political parties (Tusjinaka and Pekkanen, 2007). The federations of restaurants, pubs, hotels and amusement facilities, expressed concern about suffering economic damage (which could be limited by a partial ban only) and JTI opposed a full ban smoking (Matsuzawa, 2009).

- The motive and opportunity to select a solution. While policymakers in the central government are reluctant to introduce the bill, the new system of intergovernmental relations gave local governments the power to legislate bylaws and introduce fines to regulate behaviour. The dual representation system enabled the governor of Kanagawa prefectural government to initiate his own 
legislature regardless of intention of the assembly. Yet, the three main parties and groups, the LDP, Komeito and Kenseikai, shared the majority of the assembly, and opposed introducing a total ban on smoking in public places (Matsuzawa, 2009). The assembly worked as a 'veto player' against the governor's legislation.

The assembly exerted power to restrict the bill's provisions. In 2008, the LDP, Komeito, and Kenseiki opposed introducing a total ban. So, before the bill was formally introduced to the assembly, the prefectural government amended it several times. By the final stage of discussion in the assembly in March 2009, LDP, Komeito and Kenseikai group still planned to introduce an alternative bill. This bill would expand more significant exemptions than the original, and postpone the enforcement of administrative fines for two years. The confrontation between the governor and majority of the assembly peaked and the possibilities of failing to pass the original bill increased. At the last phase, to break the deadlock, the chair of the assembly negotiated a compromise. The governor accepted more amendments and the (Regulation) of Prevention of Passive Smoking in Public Places bill was passed in the Kanagawa prefecture in March 2009 (Matsuzawa, 2009). Perhaps the most important symbol of Japanese policy is that, even in the leading prefecture, no administrative fine has been issued (The Asahi Shimbun, 19/06/2011). Instead, the government is doing all it can to persuade small business owners and subsidise their redevelopment to accommodate the new policy.

Overall, the Kanagawa experience demonstrates a window of opportunity only for a partial ban, while the political cost of a full ban remains too high for its governor. There is high public support only for limited policy change. The governor could not draw on a groundswell of public and interest group support for his proposed changes. On the contrary, the Kanagawa prefectural government had to spend a lot of policy resources to form consensus among interest groups and acquire political legitimacy for the bill. Crucially, its experience is a best case scenario in Japan right now: there is limited opportunity to pursue tobacco control and a small minority of governors have the motive.

\section{Conclusion: identifying the conditions for evidence-based tobacco policy}

The scientific evidence on tobacco harm is identical in both countries, but there remains a major difference between tobacco policies, because the UK's tobacco policy environment has become far more conducive to policy change. By no means did it guarantee a shift to comprehensive tobacco control, but it maximised the chance that policymakers would have the motive and opportunity to select relatively strong tobacco instruments during each window of opportunity. In contrast, Japan's tobacco policy 
environment constrains opportunities for policy change even if key actors have the motivation to select strong measures. Over time, these differences accumulate to produce vastly divergent policies.

We identify broad and specific ways in which to understand these developments. The party of government seemed to be crucial, and the UK now has more venues - such as the EU and devolved governments - for issue expansion. We also focus on the importance of a wider environment, in which actors at multiple levels compete to frame tobacco as an epidemic or economic product, establish which venue's (departments of health or finance) rules matter, form networks in government, and interpret socioeconomic trends. Such dynamics underpin the selection of specific instruments during windows of opportunity.

These broad and detailed comparative accounts help us identify the conditions under which the scientific evidence, on the size of the tobacco problem and the availability of effective solutions, translates into a public policy response that its advocates would consider to be proportionate.

First, although scientific evidence helps reduce uncertainty, it does not reduce ambiguity. There is high competition to define problems, and the result of this competition helps determine the demand for subsequent evidence. In tobacco, the evidence on smoking and then passive smoking helped raise attention to public health, but it took decades to translate into a proportionate response, even in leading countries such as the UK. The comparison with Japan is crucial to show that the same evidence can produce a far more limited response, as policymakers compare the public health imperative with their beliefs on personal responsibility, civil liberties, and the economic consequences of tobacco control. Consequently, the first condition is that actors are able to use scientific evidence to persuade policymakers to pay attention to, and shift their understanding of, policy problems. This outcome is far from inevitable.

Second, this debate plays out in policy environments more or less conducive to policy change. In the UK, actors used scientific evidence to help reframe the problem; this new and dominant understanding helped give the Department of Health a greater role; the health department fostered networks with public health and medical groups at the expense of the industry; and, it emphasised reductions in opposition to tobacco control, alongside reduced smoking prevalence and economic benefits to tobacco, when pursuing policy 
change. In Japan, these conditions are far less apparent: there are multiple tobacco frames; the Ministry of Finance is still central to policy; the industry remains a key player; and, policymakers pay more attention to vocal opposition to controls and their potential economic consequences. These differences have endured despite both countries signing the FCTC. Consequently, the second condition is that the policy environment becomes conducive to policy change. Scientific evidence plays a part in reshaping that environment, but in the UK it took decades and it has yet to occur in Japan.

Third, even in favourable policy environments, it is not inevitable that major policy changes will occur. Rather, the UK experience shows the high level of contingency in the coupling of high attention to tobacco, the production of solutions introducing partial or comprehensive bans on smoking in public places, and the willingness and ability of policymakers to choose the more restrictive solution. In Japan, there has been no comparable window of opportunity, while the opportunity for a partial ban has only been produced by very few subnational governments. Consequently, the third condition is that actors generate and exploit windows of opportunity for major policy change. This condition shows the limits to the effect of scientific evidence. The evidence on the health effects of passive smoking have been available since the 1980s, but they only contributed to comprehensive bans in the UK in the mid-2000s, and they seem a long way off in Japan.

Such experiences should help advocates of evidence-informed policymaking recognise that the production and dissemination of scientific evidence is a necessary but insufficient condition for major policy change. Key actors do not simply respond to new information: they use it as a resource to further their aims, to frame policy problems in ways that will generate policymaker attention, and inform technically and politically feasible solutions that policymakers will have the motive and opportunity to select. This remains true even the evidence seems unequivocal and when countries have signed up to an international agreement which commits them to major policy change. Such commitments can only be fulfilled over the long term, when actors help change the policy environment in which these decisions are made and implemented.

\section{References}

Ackrill, R., Kay, A. and Zahariadis, N. (2013) “Ambiguity, Multiple Streams, and EU Policy.” Journal of European Public Policy 20: 871-87

Albæk, E., Green-Pedersen, C. and Nielsen, L. (2007) 'Making Tobacco Consumption a Political Issue in the United States and Denmark', Journal of Comparative Policy Analysis, 9, 1, 1-20 
The Asahi Shimbun, 18/06/2016, 'Giren kara mieru Seijika'.

The Asahi Shimbun, 12/06/2012; 'Syasetsu; Tabaco Taisaku Gyokai yori Kenkou Zyushi de'.

The Asahi Shimbun, 20/04/2008, 'Syasetsu; Kin'en Jourei Matsuzawa Chiji Ganbare!'. Asare, B., P. Cairney and D. Studlar (2009) 'Federalism and Multilevel Governance in Tobacco Policy', Journal of Public Policy, 29 (1): 79-102

ASH (2010) Smoking Statistics http://www.ash.org. uk/files/documents/ASH_106.pdf

ASH (2015) Smoking Statistics http://www.ash.org.uk/files/documents/ASH_93.pdf Bache, I. and Reardon, L. (2013) "An Idea Whose Time has Come? Explaining the Rise of Well-Being in British Politics.” Political Studies 61 (4): 898-914

Baggott, R. (1988) 'Health vs. Wealth: The Politics of Smoking in Norway and the UK', Strathclyde Papers on Government and Politics, No. 57

Baggott, R. (1986) 'By Voluntary Agreement: The Politics of Instrument Selection', Public Administration, 64, Spring, 51-67

Baggott, R. (2014) Public Health: Policy and Politics $2^{\text {nd }}$ ed. (Basingstoke: Palgrave)

Bialous, S. A., Mochizuki-Kobayashi, and Stillman, F. (2006), 'Courtesy and the challenges of implementing smoke-free politics in Japan', Nicotine \& Tobacco Research, 8 (2): 203-216.

Birrell, D. (2012a) Comparing Devolved Governance (Basingstoke: Palgrave)

Cairney, P. (2007a) 'A Multiple Lens Approach to Policy Change: the Case of Tobacco Policy in the UK', British Politics, 2, 1, 45-68

Cairney, P. (2007b) 'Using Devolution to Set the Agenda? Venue shift and the smoking ban in Scotland', British Journal of Politics and International Relations, 9, 1, 73-89

Cairney, P. (2009) 'The Role of Ideas in Policy Transfer: The Case of UK Smoking Bans since Devolution', Journal of European Public Policy, 16, 3, 471-488

Cairney, P. (2011) The Scottish Political System Since Devolution (Exeter: Imprint Academic)

Cairney, P. (2016) The Politics of Evidence-based Policymaking (London: Palgrave Pivot) Cairney, P. and Heikkila, T. (2014) 'A Comparison of Theories of the Policy Process' in (eds) P. Sabatier and C. Weible Theories of the Policy Process, Third Edition (Chicago: Westview Press

Cairney, P. and Jones, M. (2015) 'Kingdon's Multiple Streams Approach' Policy Studies Journal, 44, 1, 37-58

Cairney, P. and Mamudu, H. (2014) “The Global Tobacco Control 'Endgame”" Journal of Public Health Policy, 35, 4, 506-517 
Cairney, P. and Studlar, D. (2014) 'Public Health Policy in the United Kingdom' World Medical and Health Policy, 6, 3, 308-323

Cairney, P. and Yamazaki, M. (2013), 'Policy Transfer in Theory and Practice', International Policy Seminar: Regionalism in Europe from a comparative perspective: Suggestions to Japanese regionalism plan, National Diet Library, Tokyo

Cairney, P. and Zahariadis, N. (2016) 'Multiple streams analysis: A flexible metaphor presents an opportunity to operationalize agenda setting processes' in Zahariadis, N. (eds) Handbook of Public Policy Agenda-Setting (Cheltenham: Edward Elgar)

Cairney, P., Studlar, D. and Mamudu, H. (2012) Global Tobacco Contro (Basingstoke: Palgrave)

Cairney, P., Oliver, K. and Wellstead, A. (2016) 'To Bridge the Divide between Evidence and Policy', Public Administration Review, early view, DOI:10.1111/puar.12555

Chief of Health Service Bureau of Health, Ministry of Health, Labour and Welfare (2010), 'Judou Kitsuen Boushi Taisaku ni tsuite', 25/02/2010.

Buerk, R. (2010) 'Japan imposes 40\% cigarette tax increase', BBC News 1 October http://www.bbc.co.uk/news/world-asia-pacific-11449516

Duina, F. And P. Kurzer (2004) 'Smoke in Your Eyes: The Struggle Over Tobacco Control in the European Union', Journal of European Public Policy, 11(1): 57-77 Feldman, E. A. and R. Bayer (2004) 'Introduction', in E. A. Feldman and R. Bayer (eds) Unfiltered: Conflicts over Tobacco Policy and Public Health (Cambridge: Harvard University Press).

Greer, S. (2004) Territorial Politics and Health Policy: UK Health Policy in Comparative Perspective (Manchester: Manchester University Press)

Hirayama, T. (1981) 'Non-smoking Wives of Heavy Smokers Have a Higher Risk of Lung Cancer: A Study from Japan', British Medical Journal Clinical Research Edition, 282(6259): 183-5

Ito, S. (2001), 'Shaping Policy Diffusion: Event History Analyses of Regional Laws in Japanese Prefectures', Japanese Journal of Political Science, 2 (2): 211-235

Japan Society of Tobacco Control (2014), 'Tabaco Gyokai kara no Seiji Kenkin no Jittai ni tusite (2010-2012)', 28/11/2014,

http://notobacco.jp/seijikenkin/kenkin201012.htm

Japan Times (2016) 'Smoking rate for Japanese men falls below 30\%' 28 July http://www.japantimes.co.jp/news/2016/07/28/national/science-health/smoking-rate-

japanese-men-falls-30-first-time/\#.WJ128mZviUk

Japan Tobacco Inc. (2015), Annual Report FY2015 (Tokyo: JTI)

Japan Tobacco Inc. (2017), Brief summary of tobacco taxation, 
https://www.jti.co.jp/tobacco/knowledge/tax/index.html

Jones, Michael, D., Holly L. Peterson, Jonathan J. Pierce, Nicole Herweg, Amiel Bernal, Holly Lamberta Raney, and Nikolaos Zahariadis (2016) 'A River Runs Through It: A Multiple Streams Meta Review’ Policy Studies Journal 44.1: 13-36

Joossens, L. and Raw, M. (2014) The Tobacco Control Scale in Europe 2013 http://www.europeancancerleagues.org/images/TobaccoControl/TCS_2013_in_Europe_

\section{3-03-14_final_1.pdf}

Kanai, T., (2007), Jichi Seido, Tokyo, The University of Tokyo Press.

Keating, M. (2010) The Government of Scotland, 2nd edn (Edinburgh: Edinburgh University Press)

Kingdon, J. (1984) Agendas, Alternatives and Public Policies, New York: Harper Collins Kitamura, Y., (2003), 'Jourei no Gimu Rikou Kakuho Syuhou to shiteno Karyou', Chihou Jichi Shokuin Kensyu, 36 (4): 20-22

Levin, M. (2005), 'Tobacco Industrial Policy and Tobacco Control Policy in Japan', Asian-Pacific Law \& Policy Journal 6 (1): 44-70, (winter).

Levin, M. (2013), 'Tobacco Control Lessons from the Higgs Boson', American Journal of Law \& Medicine, 39: 471-489.

Liu, X., Lindquist, E., Vedlitz, A., and Vincent, K. (2010) "Understanding Local Policymaking: Policy Elites' Perceptions of Local Agenda Setting and Alternative Policy Selection." Policy Studies Journal 38 (1): 69-91.

Mamudu, H., Cairney, P. and Studlar, D. (2015) 'Global Public Policy: does the new venue for transnational tobacco control challenge the old way of doing things?' Public Administration, 93, 4, 856-873

Matsuzawa, S, (2009), Judo Kitsuen Boushi Jourei, Toshindo, Tokyo

Ministry of Internal Affairs and Communications (2009), Local Autonomy in Japan: Current Situation \& Future Shape,

http://www.clair.or.jp/j/forum/other_data/pdf/20100216_soumu_e.pdf

Muramatsu, M. (1997), Local Power in the Japanese State, Berkeley, University of California Press.

Muramatsu, M, and Iqbal, F., and Kume, I. (2001), Local Government Development in Post-War Japan, Oxford, Oxford University Press

Nakano, K., (2010), Party politics and decentralization in Japan and France, London, Routledge.

Nishio, M., (2001), Gyoseigaku (2nd edition), Tokyo, Yuhikaku.

Ohsugi, S., (2008), Local Assemblies in Japan, Council of Local Authorities for International Relations. 
Read, M. (1996) The Politics of Tobacco (Aldershot: Avebury)

Reed, R. S. (1986), Japanese Prefectures and Policymaking, Pittsburgh, Pittsburgh University Press.

Rhodes, R.A.W. (1988), Beyond Westminster and Whitehall, London, Unwin Hyman Samuels, R. (1983), The Politics of Regional Policy in Japan, Princeton, Princeton University Press

Studlar, D. and Cairney, P. (2014) 'Conceptualizing Punctuated and Non-Punctuated Policy Change', International Review of Administrative Sciences, 80, 3, 513-31

Tanaka, K. (2014), Tabaco Kisei wo meguru Hou to Seisaku, Tokyo, Nihonhyoronsha. Taylor, P. R. (1984) The Smoke Ring (New York: Pantheon Books)

The Mainichi Shimbun, 20/02/2014, 'Judou Kitsuen Boushi : Gimu kara Doryoku he Roudou Eiseihou Kaiseian Koutai'.

Tusjiyama, Y., and Pekkanen, R., (2007), 'Civil Society and Interest Groups in Contemporary Japan', Pacific affairs, 80 (3); 419-437

Yamazaki, M. (2010), 'Regionalism and Governing Style in the UK and Japan', Annals, 4; 111-124, Public Policy School of Hokkaido University.

Yamazaki, M. (2015), 'The Structure of Contemporary Japanese Central-Local Government Relations,' Special Edition of Annals: Frontiers in Public Policy; 29-41:, Hokkaido University Public Policy School.

Zahariadis, N. (2014) 'Ambiguity and multiple streams" in P. Sabatier and C. M. Weible (eds.), Theories of the Policy Process ( ${ }^{\text {rd }}$ ed.), Boulder, CO: Westview Press 